\title{
Ankle Arthritis in a 6-Year-Old Boy After a Tick Bite - A Case Report
}

\author{
Per-Henrik Randsborg* and Carl-Erik Naess
}

Department of Orthopedic Surgery, Akershus University Hospital, 1478 Lørenskog, Norway

\begin{abstract}
Background: Monoarthritis of the ankle is a rare condition in children, and is most often caused by a bacterial infection. Lyme disease is endemic in southern Scandinavia, and diagnosis remains a challenge. The clinical presentation of Lyme disease varies greatly, and often with considerable delay between exposure and presentation.

Case Presentation: We report a case of ankle arthritis in a boy who presented one year earlier with a tick bite on the dorsum of the foot. He was suboptimally treated with oral antibiotics for one week, and developed in the following months a painless limp. Radiographs revealed a severe arthritis of the right ankle joint with necrosis of the talus and deformation of the talocrural and subtalar joints. There was no history of malaise, fever or other systemic symptoms. He remains seronegative for antibodies against B. burgdorferi.
\end{abstract}

Conclusions: The suboptimal oral antibiotic treatment may have hindered the antibody production against $B$ burgdorferi, while not being therapeutic, resulting in severe ankle arthritis due to seronegative Lyme disease.

Keywords: Arthritis, children, seronegative Lyme disease, borreliosis.

We report a case of ankle arthritis in a boy who presented one year earlier with a tick bite on the dorsum of the foot. The tick bite occurred during summer 2005, in Mäleren, Sweden, an endemic area of Lyme disease. The patient, a previously healthy 5 year-old boy, subsequently developed an acute swelling on the dorsum of his right foot. There was no previous trauma. The local emergency physician diagnosed the tick bite and subscribed one week oral penicillin treatment (400 $\mathrm{mg}$ phenoxymethylpenicillin 3 times a day for seven days). The classical rash of erythema migrans was not observed. The acute swelling subsided over a few weeks. During fall 2005 the parents observed a gradual limping gait. The patient was referred to our orthopedic department, where radiological examination revealed an almost complete necrosis of the talus, with deformation of the talocrural and subtalar joints (Fig. 1). His calf muscles were atrophic and there was almost no ankle movement. He could fully weight-bear, had mild pain and participated in all daily activities. There was no malaise, fever or joint pain, neither any family history of juvenile arthritis nor other autoimmune diseases.

The patient was referred to our pediatric department and was tested for antibody response to B. burgdorferi. This was negative, however. Rheumatological screening tests, including Ig; RF, IgG RF and anti-CCP as well as ANA, were also negative. His hematological profile was normal, including an ESR level of 8. An open biopsy of the ankle joint was performed, showing no sign of acute inflammation (Fig 2). Blood and joint tissue cultures were negative.

We did not find any other explanation for his ankle arthritis. He developed equinovarus of the ankle and in

*Address correspondence to this author at the Department of Orthopedic Surgery, Akershus University Hospital, 1478 Lørenskog, Norway; Tel: +47 02900: Fax:+4707902140 E-mail: pran@ahus.no
February 2008 osteophytes around the talocrural and subtalar joints were removed to increase dorsiflexion. Postoperatively his foot is plantigrade and painfree. He is now fully active. The patient and his family have given their informed consent for the publication of this case report.

\section{DISCUSSION}

Borreliosis, or Lyme disease, is a common vector-borne multisystem disorder caused by the spirochete Borrelia burgdorferi. The vector is various species of Ixodes ticks. The disease is endemic in forested areas of Scandinavia and central Europe. In Norway, the annual incidence of Lyme postinfectious arthritis is $3 / 100000$ children [1].

Our patient was treated for a tick bite in the summer 2005. He was given one week of oral antibiotics, even without erythema migrans or systemic symptoms. This treatment may have hindered the antibody production against B burgdorferi, while not being therapeutic, due to the short duration. Seronegative Lyme arthritis due to early and inadequate antibiotic treatment has been reported by several authors [2-5]. Chronic Lyme disease cannot be excluded by the absence of antibodies against B. burgdorferi [6]. Further diagnostic tests were for various reasons not performed in our case, making our diagnosis uncertain. In such cases, PCR analyses for Borrelia burgdorferi antigens from synovial fluid or tissue could provide a definitive diagnosis [7]. Other diagnostic tools, such as antigen specific Lymphocyte transformation tests, are also available, but the sensitivity and specificity of the test has not been established, and it is not recommended as a routine diagnostic tool $[8,9]$.

Other causes of severe arthritis in children are bacterial and juvenile idiopathic arthritis. Unlike Lyme Arthritis, patients suffering from bacterial arthritis are systemically affected with fever, painful joints and insufficiency to weight bear. 

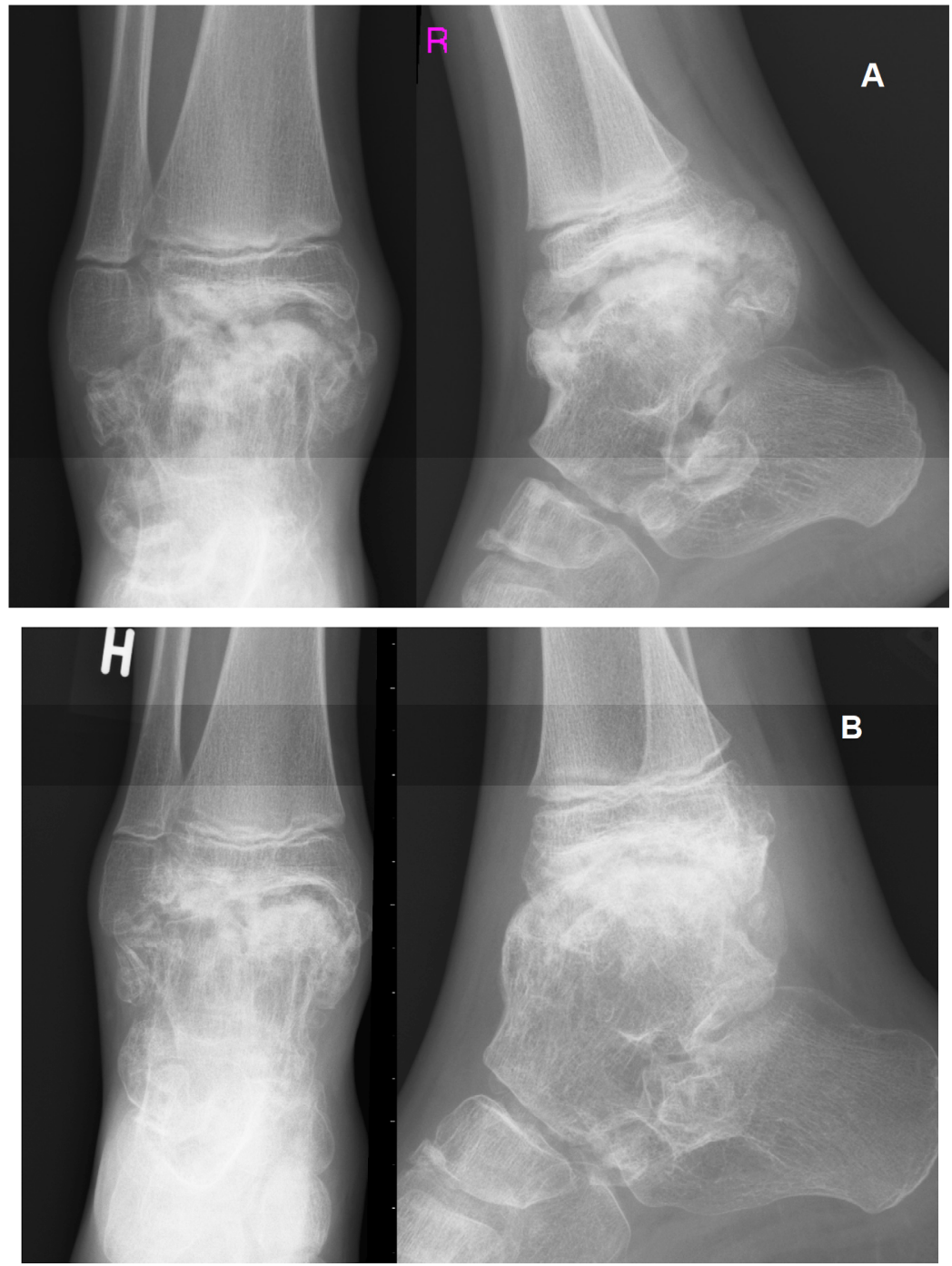

Fig. (1). Anterioposterior and lateral radiograph of the ankle at presentation (A), and two years later, after removal of osteophytes around the ankle joint to improve dorsiflexion (B).

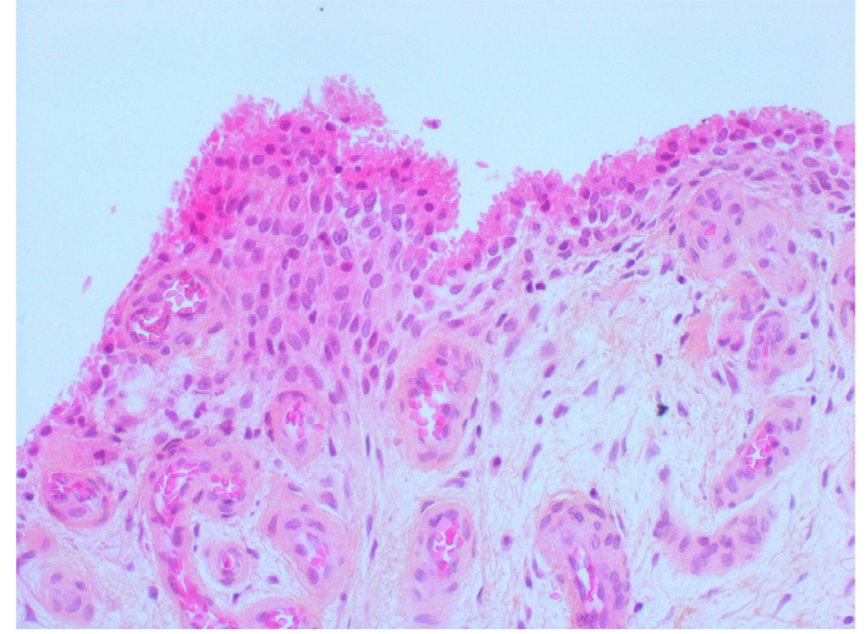

Fig. (2). Histological view of the synovium demonstrating a reactive papillary hyperplasia of the synovial membrane and proliferation of capillaries in the subsynovial tissue. The synovial lining cells show both hypertrophy and hyperplasia. There are no inflammatory cells or deposits of organic material.
The most common orthopedic manifestation of Lyme disease in children is oligoarticular arthritis, with the knee most commonly affected [10]. The arthritis is not always associated with the typical rash, erythema migrans, which affects only 50 $\%$ of children with the disease [11]. The onset of arthritis after a tick bite usually occurs within weeks or months, but as late debut as five years has been reported [12]. Other orthopedic complications include recurrent synovitis and popliteal cysts [13]. We have found no references to ankle monoarthritis due to Lyme disease in the literature.

A tick bite with absence of erythema migrans is not an indication for prophylactic antibiotic therapy. Neither is it necessary to treat persons with positive Lyme serology, but without any symptoms of Lyme disease. Treatment is based on clinical signs, and all symptoms should be treated as early as possible to shorten the duration and prevent progression of the disease. An insect bite in itself, however, is not a sign of Lyme disease.

Drugs of choice are amoxicillin, doxycillin and third generation cephalosporins with a recommended duration of therapy of 2-4 weeks [14]. 


\section{COMPETING INTERESTS}

The authors declare that they have no competing interests.

\section{CONTRIBUTIONS OF AUTHORS:}

PHR: conception of case report, writing the manuscript, literature search

$\mathrm{CEN}$ : performed surgery, revision of manuscript

\section{ACKNOWLEDGEMENT}

The authors would like to thank Dr. Vivian Cecilie Orszagh for evaluating the histological findings and processing Fig. (2).

\section{REFERENCES}

[1] Riise OR, Handeland KS, Cvancarova M, et al. Incidence and characteristics of arthritis in Norwegian children: a populationbased study. Pediatrics 2008; 121(2): e299-e306.

[2] Bianchi G, Rovetta G, Monteforte P, et al. Articular involvement in European patients with Lyme disease. A report of 32 Italian patients. Br J Rheumatol 1990; 29(3): 178-80.

[3] Hoogkamp-Korstanje JA. [Laboratory diagnosis of Lyme borreliosis]. Ned Tijdschr Geneeskd 1997; 141(48): 2339-42.

[4] Preac-Mursic V, Weber K, Pfister HW, et al. Survival of Borrelia burgdorferi in antibiotically treated patients with Lyme borreliosis. Infection 1989; 17(6): 355-9.
[5] Volkman DJ. Seronegative disease after inadequate therapy in Lyme arthritis: comment on the article by Kannian et al. Arthritis Rheum 2008; 58(7): 2212-3.

[6] Dattwyler RJ, Volkman DJ, Luft BJ, Halperin JJ, Thomas J, Golightly MG. Seronegative Lyme disease. Dissociation of specific $\mathrm{T}$ - and B-lymphocyte responses to Borrelia burgdorferi. N Engl J Med 1988; 319(22): 1441-6.

[7] Chmielewski T, Fiett J, Gniadkowski M, Tylewska-Wierzbanowska S. Improvement in the laboratory recognition of lyme borreliosis with the combination of culture and PCR methods. Mol Diagn 2003; 7(3-4): 155-62.

[8] Mygland A, Ljostad U, Fingerle V, Rupprecht T, Schmutzhard E, Steiner I. EFNS guidelines on the diagnosis and management of European Lyme neuroborreliosis. Eur J Neurol 2010; 17(1): 8-4.

[9] Valentine-Thon E, Ilsemann K, Sandkamp M. A novel lymphocyte transformation test (LTT-MELISA) for Lyme borreliosis. Diagn Microbiol Infect Dis 2007; 57(1): 27-34.

[10] Huppertz HI, Karch H, Suschke HJ, et al. Lyme arthritis in European children and adolescents. The pediatric rheumatology collaborative group. Arthritis Rheum 1995; 38(3): 361-8.

[11] Davidson RS. Orthopaedic complications of Lyme disease in children. Biomed Pharmacother 1989; 43(6): 405-8.

[12] Albert S, Schulze J, Riegel H, Brade V. Lyme arthritis in a 12-yearold patient after a latency period of 5 years. Infection 1999; 27(4-5): 286-8.

[13] Roth J, Scheer I, Kraft S, Keitzer R, Riebel T. Uncommon synovial cysts in children. Eur J Pediatr 2006; 165(3): 178-81.

[14] Franz JK, Krause A. Lyme disease (Lyme borreliosis). Best Pract Res Clin Rheumatol 2003; 17(2): 241-64. 